\title{
It's not the End of the World: emic evidence for local diversity in the Maya Long Count
}

\author{
Mark Van Stone \\ School of Arts \& Communication, Southwestern College, \\ 900 Otay Lakes Road, Chula Vista, CA 91910, USA \\ email: mvanstone@swccd.edu
}

\begin{abstract}
Examining Ancient Maya notions about prophecies and their calendar cycles, we find that they predicted no 'end of the Maya calendar'. Indeed, surviving texts and art indicate that they seem to have expected no change in the status quo whatever, for at least 4000 years into the future. This search also turned up evidence that different local schools of calendar-priests differed significantly from each other; it is entirely possible that priests in one city expected the End of the World, while their peers elsewhere believed the opposite.
\end{abstract}

Keywords. 2012 phenomenon, Maya astronomy, Maya calendar, Long Count

\section{Introduction}

A plurality of ancient Maya stelae portray a ruler standing and holding a 'Serpent Bar' tightly against his chest. This is a ceremonial object carved with an extravagant head, jaws agape, at each end of a celestial snake. Often marked with X-shaped 'sky signs' and sometimes glyphs reading 'Sky', 'Darkness', 'Sun', 'Star', and so forth, it purportedly represents the Ecliptic ${ }^{1}$, while the Ruler stands for the Milky Way.

Most of these stelae show the king in a symmetrical pose, the Bar held horizontally across his chest (e.g., at Copán). However, a substantial number (e.g., at Naranjo and Seibal) portray him holding the Bar at a jaunty angle, often about $60^{\circ}$ from the vertical (see Fig. 1).

I take this pose to represent literally the Ecliptic as it crosses the Milky Way galaxy. In Mayan languages, the words for 'snake' and 'sky' are homophonic (Kan in the north, Chan elsewhere), supporting the identification of serpent with sky.

This ' $\mathrm{X}$ ' spot in the sky, near the Galactic center, will be occupied by the sun as it rises on 21st December ${ }^{2}$ 2012. The coincidence of this solar alignment with the winter solstice has fueled the fire of speculation that the Maya aimed their Long Count (see previous chapter, pp. 183-185; Thompson 1950; Schele et al. 1993; Coe \& Van Stone

1 Both skyband and double-headed serpent represent the ecliptic, according to Schele et al. (1993: 82 \& 100). Often, as at Seibal, the skyband adorns the serpent-bar like a label. In its most simplified form, the marks on the central part - the 'bar' - of the serpent bar are repeated ' $\mathrm{X}$ 's, the oldest and most essential sign in the skyband. The king in ceremony as an Axis Mundi, equivalent to the Milky Way, is another well-known trope in Maya iconography (ibid.).

2 Most reputable Maya scholars correlate the Maya Calendar with ours using the 'GMT +2 ' correlation, which places the Maya 'Era Date' or 'Creation Date' 13.0.0.0.0 (in 3114 BC) on JDN 584285. Others, particularly those influenced by astrology, prefer the older 'GMT' correlation of JDN 584283. After the Era Date, the Maya Long Count reset like a clock at midnight, and for the past 5000 years has been counting up from zero and is now approaching 13.0.0.0.0 again. The GMT correlation places the next 13.0.0.0.0 date on 21st December 2012, while the GMT+2 yields the 23rd of December. On the 23rd, the sun will be two degrees past the galactic equator as well as past the solstice. 

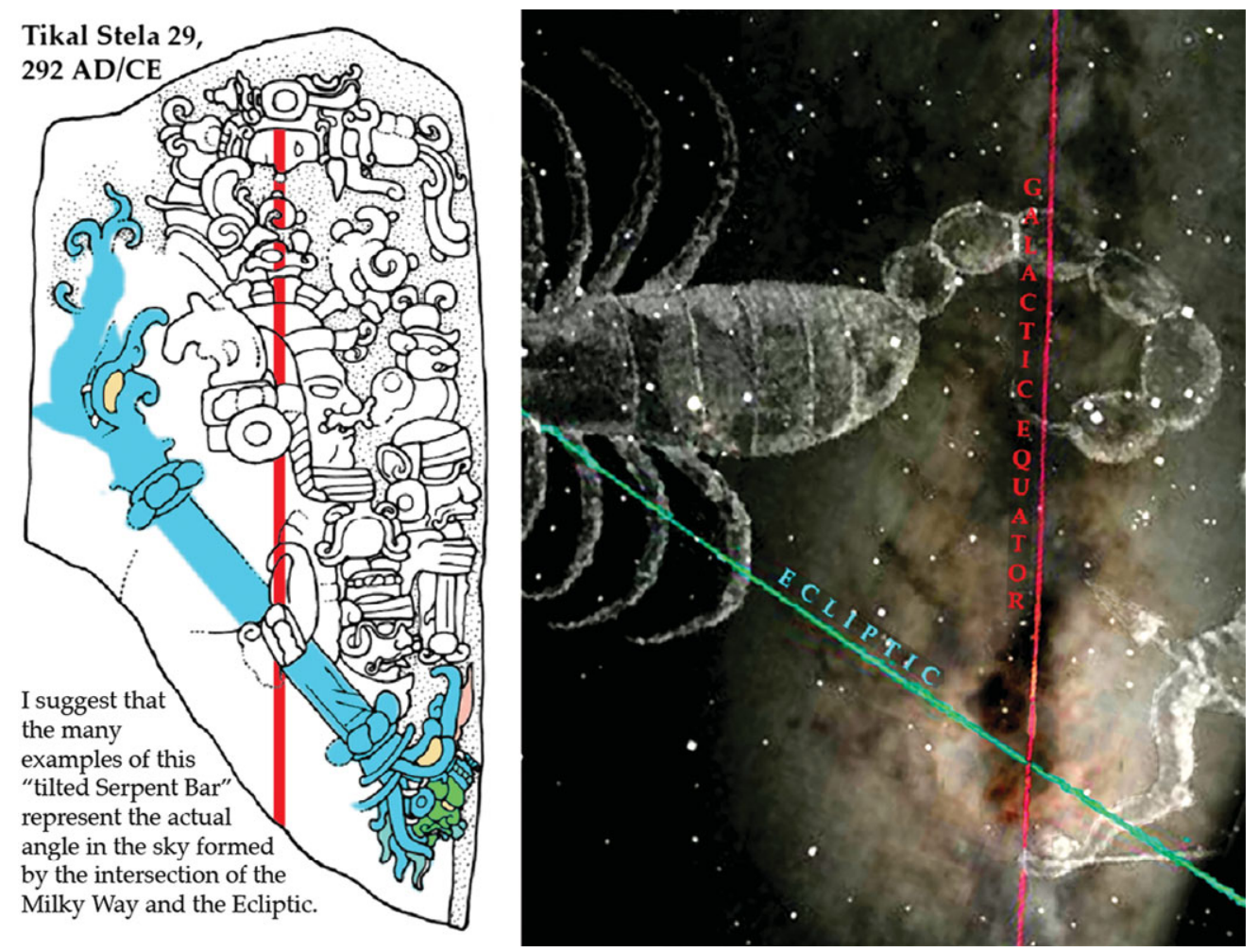

Figure 1. Tikál Stela 29, ca. $292 \mathrm{AD}$, showing a ruler holding a 'Serpent Bar' at the same angle to his body as the Ecliptic forms with the Milky Way. Drawing by Linda Schele.

2006) to end on this date. To have done this, the Late Preclassic Maya would necessarily have had an accurate knowledge of the precession of the equinoxes, a highly controversial supposition. ${ }^{3}$

The discussion whether the Maya pitched their Long Count to 'end' on a solstice in 2012 is entirely the product of modern speculation. This article examines what they tell us themselves: the scant evidence we have of actual ancient Maya attitudes toward the 13.0.0.0.0 'creation' and 'end' dates.

Actually, we only have two Maya sources that prophesy about the future 13.0.0.0.0 at all: the Chilam Balam books, and Tortuguero Monument 6. We can supplement these with a few accounts of the 13.0.0.0.0 Era Date, which give us a glimpse into Maya conceptions of that date. Finally, we examine some descriptions of the distant past and far future, which suggest that at least some Maya seers expected no big change in 2012, and further suggests that schools of priests and soothsayers differed philosophically from city to city. Upon reflection, this seems highly likely.

3 Although I believe the ancient Maya knew of precession, I doubt that they had such a precise reading that they could have predicted its position 2100 years hence. Nor did they set much store in solstices. No coronation or building dedication seems to have been scheduled for a solstice or equinox, during the entire span of Maya Classic history. The very few events that come close can be explained by coincidence. 


\section{The Chilam Balam of Chumayel}

The Chilam Balam of Chumayel is a typical indigenous highland Maya colonial document, complete with prophecies for each $K^{\prime}$ atun (20-year period), named by their final day. There are $13 \mathrm{~K}$ 'atuns in a cycle, and the whole cycle takes 256 years. Its 'Katun 4 Ahau' (ending in 2012, as well as in 1756, 1500, etc.) says:

"The Quetzal shall come, the green bird shall come. Ah Kantenal shall come. Bloodvomit shall come. Kukulcan shall come with them for a second time. The Word of God. The Itza shall come."

This requires a little explanation. Writing around 1775, the scribe seems to have been prophesying the coming $\mathrm{K}^{\prime}$ atuns based on events at the earlier ones. ${ }^{4}$ Of the $13 \mathrm{~K}^{\prime}$ atun prophecies in the cycle, two are rather noncommittal, six are bad, and two are very bad. Only three might be termed 'good', including 'Katun 4 Ahau'. (The ratings are mine.)

The passage predicts what we should expect in the two decades between 1992 and 2012. As with Nostradamus or the I Ching, colonial Maya prophets larded their pronouncements with arcane symbolism and obscure language - and plenty of dire warnings - thus allowing wide latitude.

\section{Tortuguero Monument 6}

Tortuguero Monument 6 (Fig. 2) is a seventh-century building dedication from the second-string city of Tortuguero, near Palenque. It connects its ruler's accomplishments (including several battles) to the future period-ending (i.e., 'round' Long Count date) at 13.0.0.0.0 4 Ajaw 3 Uniiw. This is the only known Classic Maya reference to the 2012 date. It prophesizes:

"It will be the end of the 13th Pik (Bak'tun). On 4 Ajaw 3rd of Uniiw, it will happen,

the witnessing of the display of Bolon-Yokte' in the great impersonation."

That's all. No "This is the End"; not even a "Reset your calendars to Zero". All that will happen is that Bolon Yokte (an obscure god or gods, whose name could mean 'Many Strides', 'Many Supports' or perhaps, literally, '9-Dog-Tree') will perform a 'great impersonation', which we shall witness. And, as we see in Fig. 2, the crucial verbs of this final sentence are partly spalled away. It is only in the past two or three years that epigraphers have come to agree on the likeliest reading of this phrase, which typically describes the preparation for a ceremony - though the monument neglects to inform us which ceremony.

\section{Cobá Stela 1, Stela 5 , and Stela 28}

Maya scribes and priests do appear to have used the same basic Long Count calendar across the land. A few inscriptions refer to its 'beginning', the Era Date 13.0.0.0.0 (see note 2), and mythological events surrounding it. Space restricts our discussion to the most salient of these, plus two other monuments that shed light on the Ancient Maya's conception of the 13.0.0.0.0 date.

4 The quetzal is a green bird sacred to the Maya for its long, maize-foliage-like tail feathers. Quetzal in Nahuatl, like its Maya equivalent $K^{\prime} u k^{\prime}$, means 'feather'; Quetzalcoatl in Nahuatl, like its Mayan equivalent $K^{\prime} u k^{\prime} u l k a n$, means 'Feathered Serpent'. Ah Kantenal is a little-known supernatural being ('He of the yellow tree place') named for a medicinal arboreal species. The Itza are a Maya people, founders of eponymous Chichén Itza. 'Blood-vomit' probably refers to one of the European-introduced diseases raging through the Maya lands after 1492, during the previous 'Katun 4 Ahau'. 


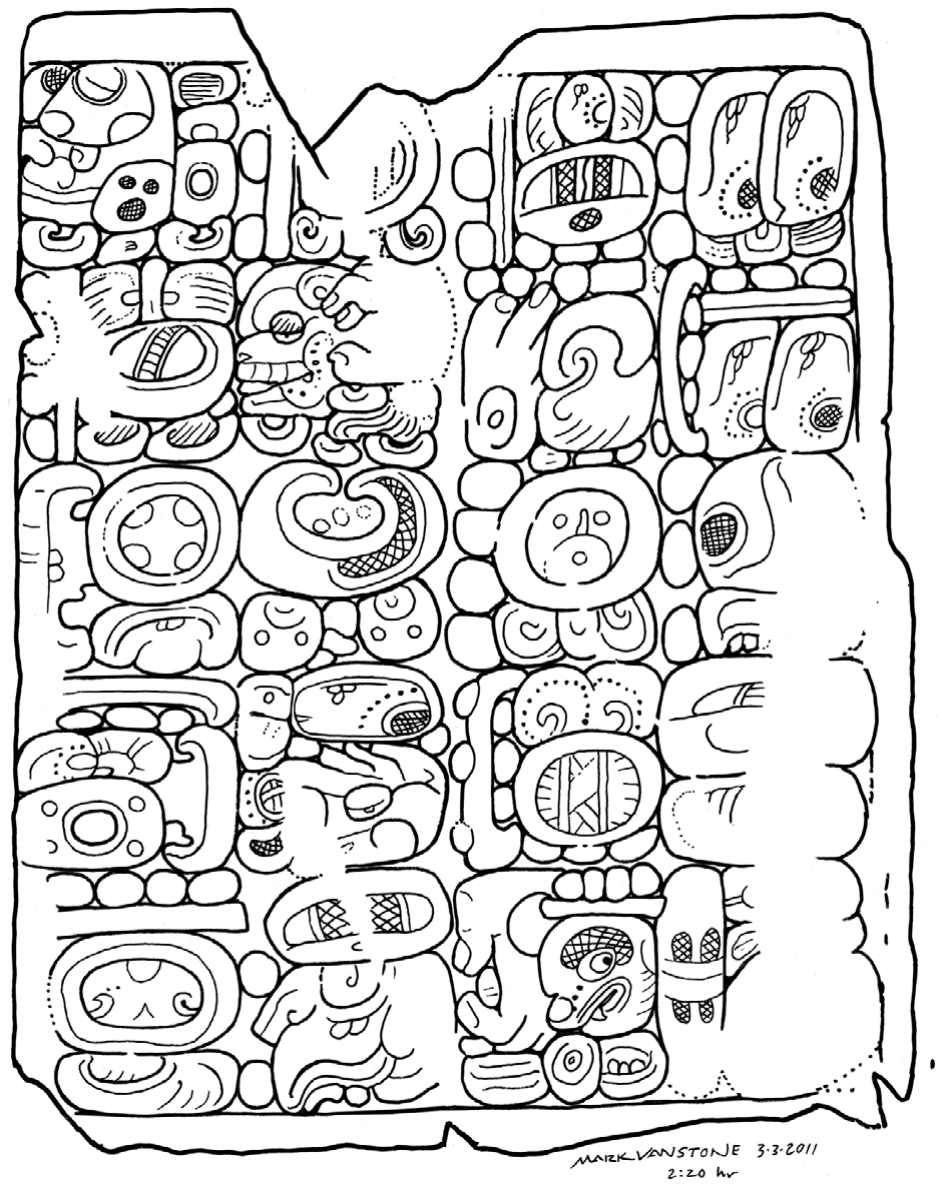

Figure 2. Right wing of Tortuguero Monument 6, late 7th century AD/CE. The Calendar Round date 4 Ajaw 3 Uniiw (formerly 3 $K^{\prime} a n k$ in) can be seen at the right end of the third row. Drawing by Mark Van Stone.

Two dozen stelae from Cobá bear the eroded vestiges of very long texts, now, sadly, largely illegible. They all portray the ruler in the same ceremony, wearing the same costume. Standing on the hunched-over bodies of captives, he holds a Serpent-Bar diagonally across his chest. Three of these accounts begin with a remarkable Long Count date:

"On 13.13.13.13.13.13.13.13.13.13.13.13.13.13.13.13.13.13.13.13.0.0.0.0,

4 Ajaw 8 Kumk u (the Era Date), the image(?) changed, the 13th Pik ended, ..."

On Stela 1, eight eroded glyphs then lead to another Long Count date in then-modern times.

What is remarkable about this monument is its preposterous 24-digit Long Count. Each higher order of time measurement is twenty times its successor, so this date includes units of time measurement on the order of $10^{30}$ years. $^{5}$

The Maya possessed one of the few ancient numerical systems equipped with placevalue and zero. Alphabetic number-systems like those used in ancient Palestine, Greece

${ }^{5}$ In fact, very few Maya Long Counts contain more than the customary five digits. I suspect that Trans-Bak'tun LCs never appeared before the Late Classic, and when they eventually got around to it, calendar priests in each place developed individual interpretations of what those higher-order coefficients would be. For example, the eight-digit LC on Tikál Stela 10, ostensibly marking an historical date, carries none of the expected $13 \mathrm{~s}$ in the upper orders. It is 1.11.19.9.3.11.2.??, where the last five digits are the usual five. The monument's style is concordant with the year 9.3.11.x.x. 
and Rome have increasing difficulty writing any number over a thousand. The scribes of Cobá were showing off. They wrote this enormous number just because they could.

Maya Long Counts invariably reset the Era Date odometer from 13 Pik (13 Bak'tuns) back to 1 , so one might assume that the next order up, also at 13, would reset as well, and perhaps the next, and the next, and on up. In other words, Cobá's scribes recorded a special date, one that would never again occur, because when the next periodending Bak'tun-counter clicks over (presumably) in 2012, the order above it should have a coefficient of one, not thirteen. After one comes two, and the higher orders would not line up all $13 \mathrm{~s}$ again for a nonillion years or so. So, we might infer from that string of $13 \mathrm{~s}$ that the Era Date of 3114 BC was unique, fundamentally different from the imminent 13.0.0.0.0 in 2012 AD.

\section{Yaxchilan Hieroglyphic Stairway 2, Step VII}

This historical text at Yaxchilan (see Fig. 3) echoes the Long Long Count date on the Cobá stelae. Its first eight digits record the coefficients of the eight orders of time-units above the Bak'tun, just as the Cobá LC dates record 19 orders above the Bak'tun.

The surprise here is that the coefficient of the Piktun (the next higher order above the Bak'tuns) is (still) 13. As mentioned above, one might expect that, when the Bak'tun coefficient reset to 1 , the Piktun coefficient would also have reset, triggering the nexthigher-order coefficient, etc. Alternatively, it might perhaps have risen to 14. But Yaxchilan HS2 Step VII's Piktun coefficient stays stuck at 13. Apparently the calendar-priests of Yaxchilan (and perhaps also at Cobá) considered these higher-order coefficients as purely symbolic; they do not accumulate time like the 'real' lower-order coefficients. Perhaps the priests in these cities did expect that the Long Count would restart after the 13.0.0.0.0 in December 2012. They do not, unfortunately, tell us explicitly one way or another.

However, I think that scribes and priests in some other polities disagreed with either interpretation. Certainly the Palenque scribes did. Our final example shows why.

\section{The Temple of Inscriptions at Palenque}

The Palenque Temple of Inscriptions, though not mentioning past creation(s), does reveal some critical attitudes about the future (at least among the local priesthood). In the final section of its long inscription extolling the great Pakal, buried therein, the text looks ahead to two important period-endings: 10.0.0.0.0 and 1.0.0.0.0.0 (the day the Long Count 'odometer' will click up to six digits). The first corresponds to $830 \mathrm{AD} / \mathrm{CE}$, some 137 years in the artist's future.

The second, more important to us, is still a long way off: $4772 \mathrm{AD} / \mathrm{CE}$. It is ten Bak'tuns still farther in the future, exactly twice as far from the 4 Ajaw 8 Kumk $u$

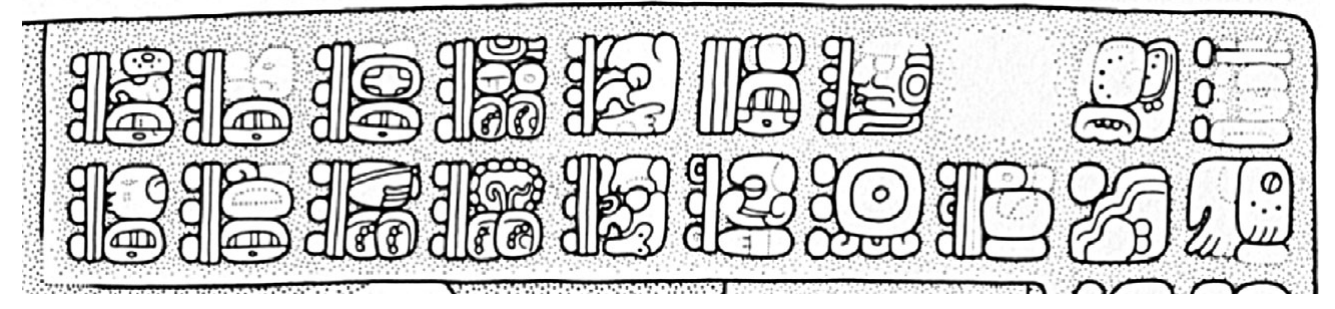

Figure 3. Hieroglyphic Stairway 2, Step VII, detail. Dated 13.13.13.13.13.13.13.13.9.13.15.6.9, ...3 Muluk. After Graham (2004). 
Creation as 10.0.0.0.0. The scribes announce a numerologically important connection of this date to the life of their late, beloved ruler: just eight days later, on 1.0.0.0.0.8, 5 Lamat $1 \mathrm{Mol}$, would be the anniversary of Pakal's coronation on 9.9.2.4.8, 5 Lamat $1 \operatorname{Mol}(612 \mathrm{AD} / \mathrm{CE})$.

This is not just any random anniversary. It marks a span of 80 Calendar Rounds, in other words $4 \times 20 \times 52$ years, a number rife with numerological significance, which would occur just eight days away from the turning of the Piktun. Imagine the quiver of excitement in the scribe who discovered this conjunction!

In terms of understanding the 2012 date, this text is critical. It tells us two important things. First, the Palenque priest-prophets did not expect the Long Count calendar to reset after it reached 13. Instead, the next Bak'tun will be 14.0.0.0.0, and then 15.0.0.0.0, and on up to the 20th, when it finally resets and the odometer clicks over the next-higher digit to reach 1.0.0.0.0.0. The text explicitly tells us so:

(From TI West, G2:) "Now, from when he became Ajaw, K'inich Janab Pakal, Sacred Ajaw of Palenque, eight days, five-score days, ten years, eleven $\mathrm{K}^{\prime}$ atuns, and ten Bak'tuns after 5 Lamat $1 \mathrm{Mol}(612 \mathrm{AD} / \mathrm{CE})$, will be the first Piktun. 8 days after this 'seating of the stone' (period-ending) on 10 Ajaw 13 Yaxk' in (1.0.0.0.0.0, = 4772 AD/CE) it will be 5 Lamat 1 Mol again."

Second, they confidently imply that the coronation date of Pakal will be remembered, and celebrated for a long time. They tell us that they expect this status quo to last for over 4000 years, at least. This answers an important question that has arisen in the wake of all the brouhaha about the so-called 'end of the Maya calendar'. It be not a date of Destruction, nor of Transformation for the Better. Life will go on as before. ${ }^{6}$

\section{Concluding remarks}

So what did Maya scribes and astronomers think of the future 2012 date? The answers we can collect from the original texts are slim and fragmentary at best. But there is enough evidence here to suggest that most Maya expected nothing to happen. The date 13.0.0.0.0, like Y2K, would be just another period-ending, just another year. I have not found a single piece of evidence to suggest that any Maya expected anything more significant than the dressing-up of Bolon Yokte' for an impersonation ceremony. Further, some scribes, in Palenque at least, clearly implied that nothing significant would happen on the 2012 date, not even a re-setting of the calendar.

Diversity between cities assures us that some Maya must have expected 2012 to herald important events and transformations - possibly even re-creations. But we haven't found any emic evidence for it-yet.

\section{References}

Coe, M. D. \& Van Stone, M. 2006, Reading the Maya Glyphs, 2nd edition, Thames \& Hudson, London \& New York.

Graham, I. 2004, Corpus of Maya Hieroglyphic Inscriptions, Volume 3: Part 3: Yaxchilan, Peabody Museum Press, Cambridge MA.

Schele, L., Freidel, D., \& Parker, J. 1993, Maya Cosmos-Three Thousand Years on the Shaman's Path, Morrow \& Co., New York.

Thompson, J. E. S. 1950, Maya Hieroglyphic Writing, Publication 589, Carnegie Institution of Washington, Washington, DC.

${ }^{6}$ The ancient Maya also failed to foresee the Spanish Conquest, a genuine end-of-their-world. This casts a shadow of doubt on their soothsaying skills in general. 